\title{
Experimental Investigation of Radial Gas Dispersion Coefficients in a Fluidized Bed
}

\author{
Jiří Štefanica ${ }^{1}$ Jan Hrdlička ${ }^{1}$ \\ ${ }^{1}$ CTU in Prague, Faculty of Mechanical Engineering, Department of Energy Engineering, Technická 4, \\ 16607 Praha, Czech Republic
}

Correspondence to: jiri.stefanica@seznam.cz

\begin{abstract}
In a fluidized bed boiler, the combustion efficiency, the $\mathrm{NO}_{X}$ formation rate, flue gas desulphurization and fluidized bed heat transfer are all ruled by the gas distribution. In this investigation, the tracer gas method is used for evaluating the radial gas dispersion coefficient. $\mathrm{CO}_{2}$ is used as a tracer gas, and the experiment is carried out in a bubbling fluidized bed cold model. Ceramic balls are used as the bed material. The effect of gas velocity, radial position and bed height is investigated.
\end{abstract}

Keywords: fluidized bed, gas mixing, radial dispersion.

\section{Introduction}

Fluidized bed combustion technology is an efficient and ecological way of combusting low quality fuels. The fuel is combusted in a bed of inert material that is brought to a fluidized state by passing through air. In a fluidized state, the bed particles are in force equilibrium, resulting in fluid-like behaviour of the bed. Extensive gas and solid mixing inside the fluidized bed provides a large active surface for all chemical reactions, and also for heat transfer. As a result, the combustion temperature can be lower than for other types of combustion, while high combustion efficiency is achieved. A temperature range of $800-950{ }^{\circ} \mathrm{C}$ is usually used, providing ideal conditions for in-situ desulphurisation and reduction of $\mathrm{NO}_{X}$. This temperature is also necessary to prevent agglomeration of the bed material.

A detailed fluidized bed behaviour description is needed for the design and control of a fluidized bed boiler. There are many quantities for characterizing a fluidized bed. One of the most important characteristics is the extent of mixing, because it rules the intensity of all mass and heat transport processes. Gas and solid dispersion coefficients in axial and radial direction are used to describe the extent of mixing in the bed. This paper will present an experimental evaluation of the gas dispersion coefficient in radial direction $\mathrm{D}_{g r}$ for a bed of ceramic balls. Ceramic balls are not a typical inert bed material; quartz sand and coal ash are more widely used. Ceramic balls have recently come under consideration for use in combustion of biomass and waste derived fuels [1].
The most widely used method for dispersion coefficient evaluation is the tracer gas method. This method uses a suitable tracer gas, which is injected in a fluidized bed at one point. The concentration of the tracer gas in the primary fluidization gas is then measured at other points of the bed. Gas dispersion coefficients can be determined using an appropriate model. The tracer gas experiment methodology is presented in detail in [2]. The step response tracer gas method is suitable for evaluating the axial dispersion coefficient $D_{g a}$. Some authors have used the tracer gas method with steady state to determine also $D_{g r}$, the radial dispersion coefficient [3-5]. Considering the similarities of the two types of experiments, all tracer gas related studies have been taken into account. Some authors (e.g. $[5,7])$ consider axial dispersion to be less important than radial dispersion. In this work the steady state tracer gas method was used to determine the gas dispersion coefficients in radial direction $D_{g r}$.

\section{Theory}

The radial gas dispersion coefficient has been evaluated by the steady state tracer gas method. Various tracer gases have been described in the literature. We selected $\mathrm{CO}_{2}$ for our experiment. After setting the tracer gas flow rate, it was necessary to wait for the tracer gas concentration to stabilize and achieve a steady state. The tracer gas concentration was then measured at the investigated height, at points with different radial positions, see the concentration profiles for heights $5-20 \mathrm{~cm}$ and fluidization velocity of $0.44 \mathrm{~m} / \mathrm{s}$ in Figure 1. 


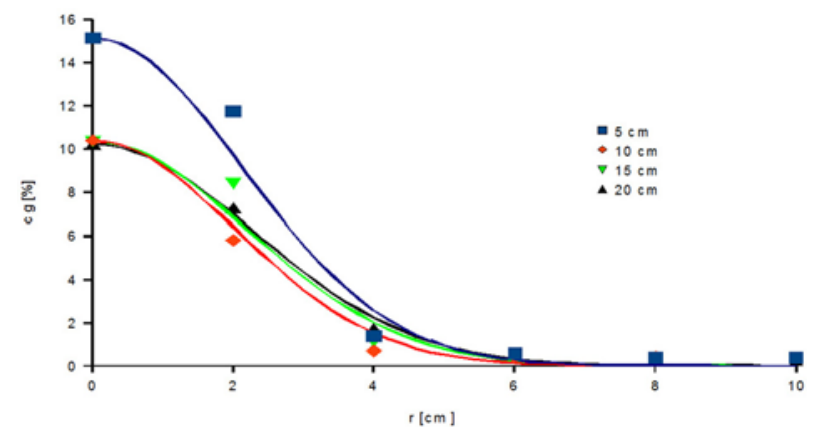

Figure 1: Radial dispersion profiles for ceramic balls, $0.44 \mathrm{~m} / \mathrm{s}$

The dispersed plug flow model from equation (1) can be used for the evaluation. Assuming dispersed plug flow, the concentration profiles should agree with equation (2), where $x$ is the radial position and $x_{m}$ is the radial position where the tracer gas concentration reaches half of the maximum value. According to [5], the solution for sufficiently distant boundaries is given by equation (3), and $D_{g r}$ can be calculated by equation (4).

$$
\begin{aligned}
u \frac{\partial C_{g}}{\partial h} & =D_{g r}\left[\frac{1}{x} \frac{\partial}{\partial x}\left(x \frac{\partial C_{g}}{\partial h}\right)\right]+d_{g a} \frac{\partial^{2} C_{g}}{\partial h^{2}} \\
\frac{C_{g}}{C_{a}} & =\left(\frac{1}{2}\right)\left(\frac{x^{2}}{x_{m}^{2}}\right) \\
\frac{C_{a}}{C_{\infty}} & =\frac{u R^{2}}{H D_{g r}} \\
D_{g r} & =\frac{u \cdot R \cdot C_{\infty}}{H} \cdot C_{g}
\end{aligned}
$$

The results can also be seen in terms of dimensionless numbers as the dependence of the Peclet number from equation (5) and the Reynolds particle number from equation (6).

$$
\begin{aligned}
P e & =\frac{L \cdot u}{D} \\
R e_{p} & =\frac{D_{p} \cdot u \cdot \varrho_{g}}{\mu}
\end{aligned}
$$

\section{Experimental}

The experiment was carried out in a bubbling fluidized bed cold model, see Figure 2. Considering the ambient temperature of the investigated bed, the model was made out of a $220 \mathrm{~mm}$ plexiglass cylinder to enable visual observation of the experiment. The body of the model was supported by a steel tripod stand 1. The fluidization air was supplied by an air fan in the lower section 2. Tracer gas was injected by pipe 3 in the middle of the perforated plate distributor 5 (open area of $2.51 \%$ ) that was supporting the fluidized bed. $\mathrm{CO}_{2}$ was used as a tracer gas, for safety reasons and also as a readily available detection method. In the wind-box section 4 between the fluidization air inlet and the distributor plate, the air flow became steady. The tracer gas concentration was measured through the access points 6 .

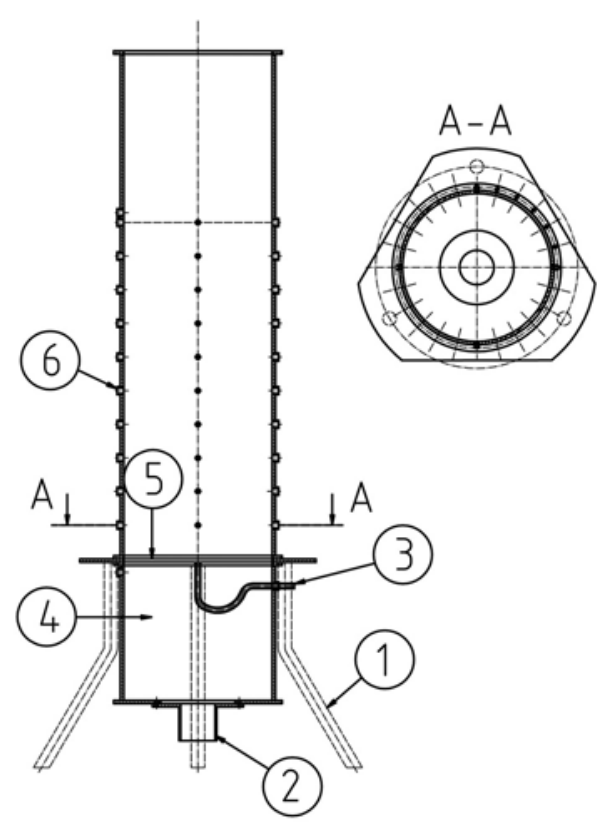

Figure 2: Experimental apparatus

The tracer gas concentration was measured using an ASEKO Air CmHn non-dispersive infrared gas analyser.

A bed of ceramic balls was used for the $D_{g r}$ investigation. The material properties are presented in Table 1. The dependence of $D_{g r}$ on mean fluidization velocity and bed height was investigated.

Table 1: Material properties

\begin{tabular}{|l|c|}
\hline & Ceramic balls \\
\hline$\rho\left[\mathrm{kg} / \mathrm{m}^{3}\right]$ & 800 \\
\hline$\varepsilon[-]$ & 0.34 \\
\hline$\Phi[-]$ & 0.95 \\
\hline$D_{p}[\mathrm{~mm}]$ & 3.11 \\
\hline$u_{m f}[\mathrm{~m} / \mathrm{s}]$ & 0.49 \\
\hline
\end{tabular}

During the experiment, the tracer gas flow rate was kept below $1.5 \%$ of the primary fluidization air flow rate. Bed heights of 5, 10, 15 and $20 \mathrm{~cm}$ were measured. Fluidization velocities of $0.44 \mathrm{~m} / \mathrm{s}$, $0.58 \mathrm{~m} / \mathrm{s}, 0.73 \mathrm{~m} / \mathrm{s}$ and $0.88 \mathrm{~m} / \mathrm{s}$ were used, representing $(1-2) \cdot u_{m f}$. The velocities were chosen in accordance with the flow rate measurement capabilities. 


\section{Results and discussion}

The $D_{g r}$ values that were obtained are shown in Figures 3-6. The values varied between $0.26-4.68 \mathrm{~cm}^{2} / \mathrm{s}$, which is in agreement with the findings of other authors. The measurements showed the same trend for all conditions. Regardless of bed height or fluidization velocity, two peak values were observed, marking the regions where the radial gas mixing is most intensive. The first peak is the region in centre of the bed, and the second peak region is near the wall. It can also be observed that, while the extent of mixing decreases with increasing fluidization velocity in the centre of the bed, the situation is reversed near the wall. With increasing gas velocity the wall region gains in significance, due to the enhanced gas and solid back mixing that takes place in the region near the walls.

It can also be observed that radial gas mixing decreases with increasing bed height. In the course of varying the bed height, the most significant difference was observed when the bed height was increased from $5 \mathrm{~cm}$ to $10 \mathrm{~cm}$. The drop in the extent of mixing was less significant for further increases in bed height.

The results in terms of dimensionless numbers are shown in Figure 7. The expected linear increase of Pe with $R e_{p}$ was observed. For higher beds, the dependence on $R e_{p}$ increased. For lower bed heights, only a slight increase or even stagnation was observed.

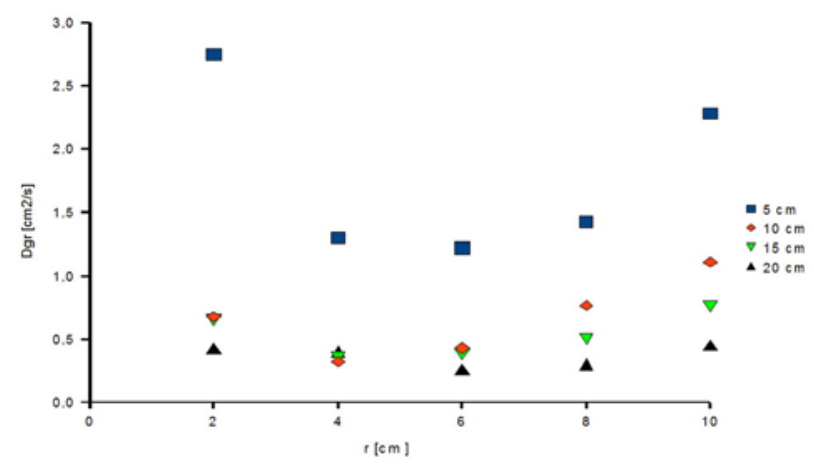

Figure 3: $D_{g r}$ for ceramic balls, $1 \cdot u_{m f}$

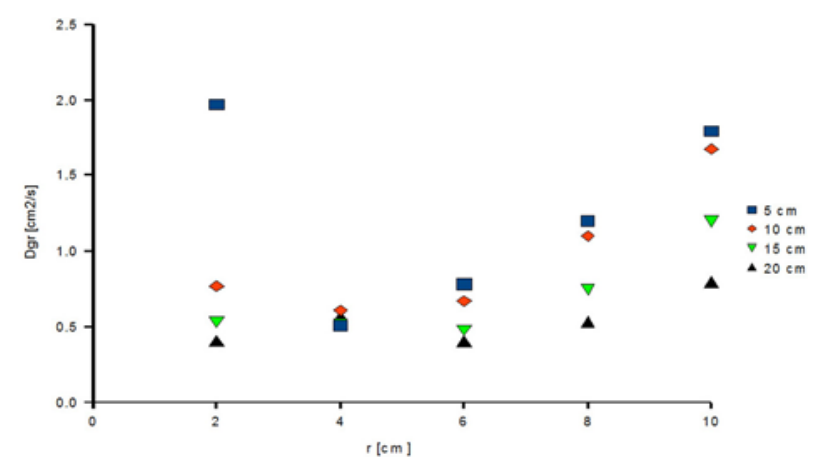

Figure 4: $D_{g r}$ for ceramic balls, $1.33 \cdot u_{m f}$

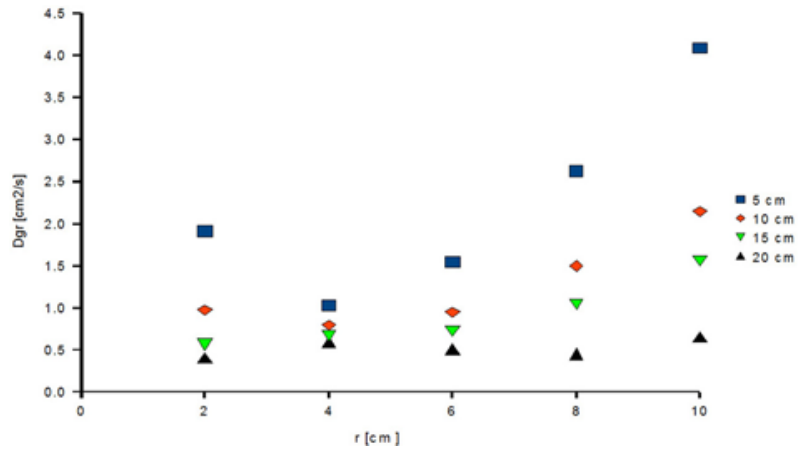

Figure 5: $D_{g r}$ for ceramic balls, $1.66 \cdot u_{m f}$

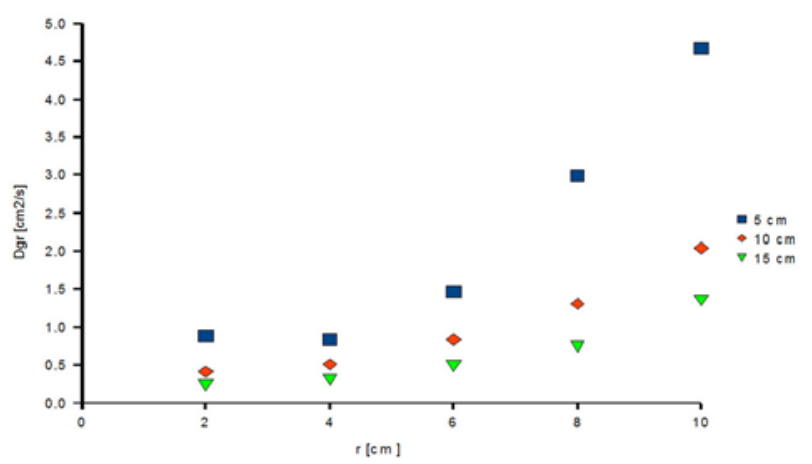

Figure 6: $D_{g r}$ for ceramic balls, $2 \cdot u_{m f}$

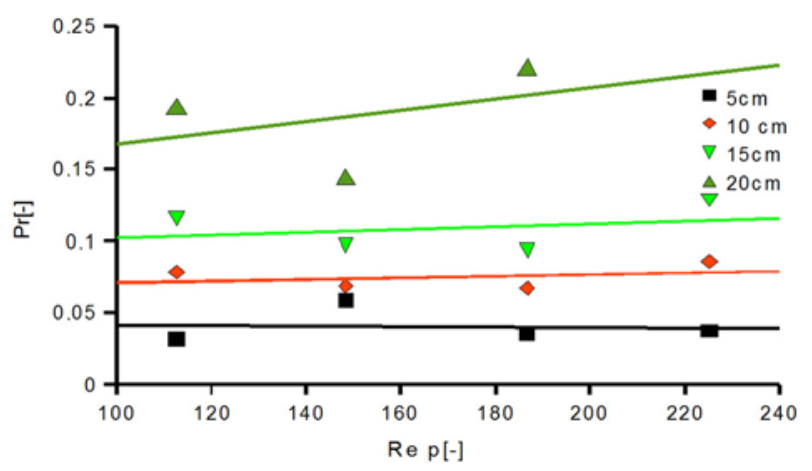

Figure 7: Dimensionless parameters

\section{Conclusion}

This paper has described how the experimental apparatus for radial gas dispersion coefficient evaluation was designed and how a steady state tracer gas experiment was conducted. Ceramic balls were used as the bed material. The effects of fluidization gas velocity and bed height were investigated.

For the conditions that were used, the radial gas dispersion coefficient values were determined to be $0.26-4.68 \mathrm{~cm}^{2} / \mathrm{s}$. This is in agreement with previous experiments for a bubbling bed, where $D_{g r}$ values of $1-5 \mathrm{~cm}^{2} / \mathrm{s}$ were mostly found.

The highest value on each level was found either in the centre of the bed or at the wall. With increasing velocity, the peak near the wall was found 
to increase, while the peak in the bed centre was decreased. The radial gas dispersion coefficients were found to decrease with bed height. Linear dependence of Pe on $R e_{p}$ was found. For higher beds, the dependence on $R e_{p}$ increased. For lower bed heights, the $\mathrm{Pe}$ value could be considered to be independent from $R e_{p}$ taking into account the measurement uncertainty.

\section{Legend}

\begin{tabular}{|c|c|}
\hline$\varepsilon[-]$ & void fraction \\
\hline$\Phi[-]$ & sphericity \\
\hline$\mu[\mathrm{Pa} \cdot \mathrm{s}]$ & dynamical viscosity \\
\hline$\rho\left[\mathrm{kg} / \mathrm{m}^{3}\right]$ & density of the bed material \\
\hline$\rho_{g}\left[\mathrm{~kg} / \mathrm{m}^{3}\right]$ & fluidization gas density \\
\hline$c_{a}[$ vol. \%] & $\begin{array}{l}\text { maximal concentration of the } \\
\text { tracer gas for a given height } \\
\text { measured at the centre of the } \\
\text { bed }\end{array}$ \\
\hline$c_{g}[$ vol. $\%]$ & $\begin{array}{l}\text { concentration of tracer gas at } \\
\text { a given point }\end{array}$ \\
\hline$c_{\infty}[\operatorname{vol} . \%]$ & $\begin{array}{l}\text { concentration of tracer gas } \\
\text { after perfect mixing with the } \\
\text { fluidization gas }\end{array}$ \\
\hline$D[\mathrm{~m}]$ & bed diameter \\
\hline$D_{g a}\left[\mathrm{~m}^{2} / \mathrm{s}, \mathrm{cm}^{2} / \mathrm{s}\right]$ & $\begin{array}{l}\text { gas dispersion coefficient in } \\
\text { axial direction }\end{array}$ \\
\hline$D_{g r}\left[\mathrm{~m}^{2} / \mathrm{s}, \mathrm{cm}^{2} / \mathrm{s}\right]$ & $\begin{array}{l}\text { gas dispersion coefficient in } \\
\text { radial direction }\end{array}$ \\
\hline$D_{p}[\mathrm{~m}]$ & particle diameter \\
\hline$L[\mathrm{~m}]$ & characteristic dimension \\
\hline$x[\mathrm{~m}]$ & $\begin{array}{l}\text { radial distance from the } \\
\text { vertical axis of the bed }\end{array}$ \\
\hline$x_{m}[\mathrm{~m}]$ & value of $x$ where $\frac{C_{g}}{C_{a}}=\frac{1}{2}$ \\
\hline
\end{tabular}
$u[\mathrm{~m} / \mathrm{s}]$
mean gas velocity
$u_{m f}[\mathrm{~m} / \mathrm{s}]$
gas velocity for minimal
fluidization
$P e[-]$
Peclet number
$R e_{p}[-]$
Reynolds number for particles

\section{References}

[1] Hrdlička, J., Obšil, M., Hrdlička, F.: Field Test of Waste Wood Combustion Using Two Different Bed Materials, In Proceedings of the 16th SCEJ Symposium on Fluidization and Particle Processing. Tokyo : The Society of Chemical Engineers, Japan, 2010, p. 40-43.

[2] Kunii, D.: LEVENSPIEL Fluidization Engineering, Butterworth - Heinemann, 1991.

[3] Namkung, W., Kim, S. D.: Radial Gas Mixing in a Circulating Fluidized Bed, Powder Technology, 113, 2000, p. 23-29.

[4] Sternéus, J., Johnsson, F., Leckner, B.: Characteristics of Gas Mixing in a Circulating Fluidised Bed, Powder Technology, 126, 2002, p. 28-41.

[5] Chyang, C.-S., Han, Y.-L., Chien, C.-H.: Gas Dispersion in a Rectangular Bubbling Fluidized Bed, Journal of the Taiwan Institute of Chemical Engineers, 41, 2010, p. 195-202.

[6] Sane, S. U. et al.: An experimental and modelling investigation of gas mixing in bubbling fluidized beds. Chemical engineering science, 51, 1996, p. $1133-1147$.

[7] Atimtay, A., Cakaloz, T.: An Investigation on Gas Mixing in a Fluidized Bed, Powder Technology, 20, 1978, p. 1-7. 